\title{
Stress and scenario tests in the context of a Romanian non-life insurance company Aurora Elena DINA (MANOLACHE)
}

\author{
University of Economic Studies, Bucharest, Romania \\ Aurora_dina86@yahoo.com
}

PICBE | 149

\begin{abstract}
The main aim of the article is to assess the vulnerabilities and resilience of a Romanian nonlife insurance company in the context of different predefined insurance stress scenarios: natural catastrophe scenario and business scenario. The natural catastrophe scenario consists in two distinct scenarios: earthquake and flood, which were carried out separately and aggregated based on three stress factors: increasing by 15\% of PML, increasing by 5\% of the gross best estimate claim provisions and reinsurer's incapacity to pay. The business stress scenario was based on four stress parameters: increasing by $3 \%$ of the claims provisions due to the inflation impact, increasing by 10\% of the gross earned premium for MTPL due to the legislative changes, increasing by $15 \%$ of the claims provisions for MTPL due to the increase of frequency and severity of the losses induced by the exposure growth as a result of the lower premiums and decreasing by $10 \%$ of the ceded best estimate. The results of the stress testing shown that the insurer is more sensitive to business scenario compared to natural catastrophe scenario due to the significant exposure on the MTPL line of business. High exposure to earthquake risk is a characteristic for Romania and the stress testing results confirm the vulnerability of the insurer to the earthquake scenario (non-compliance of the solvency capital requirements), due to the biggest impact of the factor: reinsurer's incapacity to pay. Therefore, the quality of reinsurance is very important for Romanian insurance companies to be able to manage the risks arising from the seismic events and to be compliant with the regulatory solvency capital requirements.
\end{abstract}

Keywords: Solvency II, non-life insurance, stress and scenario tests, SCR, MCR, own founds.

\section{Introduction}

Implementation of the new regulatory solvability framework, Solvency II, starting with January 2016, by the European insurance market was considered a success with regard to the contribution of the financial sector stability and a better policyholders' protection. Solvency II has brought major changes in insurance sector such as the solvency capital requirements calculation and risks' quantification by insurance companies, as well as supervisors' risk assessment, resulting in a substantial improvement in the profitability and solvency position of the European insurance industry.

Solvency II regulatory regime is structured into three pillars which cover: the riskbased capital requirements in Pilar I, qualitative requirements in Pilar II and reporting and disclosure requirements to the supervisor and public in Pillar III. The Pillar II includes a considerably high level of detail on the principles and requirements of the governance system focused on the following main aspects: general governance requirements, fit and proper requirements, risk management system and functions. As part of an insurer's risk management system, Own Risk and Solvency Assessment (ORSA) is an important process that aims to ensure a comprehensive and complex understanding of insurance company risks. This report which usually is prepared annually allows supervisors and managers to form an improved view about the ability of the insurer to withstand financial stress. The 
undertaking's ORSA policy should involve the performance of a range of stress and scenario tests and other relevant analysis in order to ensure the insurer's overall capital needs in conformity with the solvability legislation even after adverse events.

Considering that the insurance activity is based on the uncertainty dealing, an insurance company needs to assess a wide set of possible outcomes that could adversely impact the current and expected future financial position of the company. Stress testing represents a powerful management tool used to identify, quantify and manage the insurer's risks and buffer solvency adequacy by scenario and sensitivity testing. A forward-looking stress testing allows to evaluate the insurance company's robustness by simulation of unexpected but plausible shocks which have not previously occurred, in both insurer-specific and market-wide stress scenario. The reason for which it is necessary to assess scenarios is to prepare the insurer in case similar events will occur and quantify the consequences of their adversely impact on the company's solvency position. Should such these defined hypothetic scenarios materialize, the insurer will be able to manage the risks arising from these situations and to be compliant with the regulatory solvency capital requirements.

The main purpose of the article is to assess the vulnerabilities and resilience of a Romanian non-life insurance company in the context of different predefined insurance shocks and scenarios. The research paper provides an overview of the way in which an insurer is able to manage its risk over a set of plausible adverse scenarios, to quantify the scenarios impact on the its balance sheet / risk capital requirements and draw the conclusions with respect to its ability to fulfill the obligations to their policyholders and the compliance with regulatory solvency framework (principles of Directive 2009/138/EC, Commission Delegated Regulation (EU) 2015/35, consultation papers and other local solvency regulations issued by the national supervisory authority) under adverse predefined insurance scenarios. The baseline of the stress testing is the impact of stress scenarios and not on a pass/fail relative to a predetermined threshold.

The article is set out as follows. First section presented an introduction in the context of Solvency II and defined the terms "test stress" and "scenario analyses" used in the performance of ORSA report. The second section contained an overview of the literature review based on the different studies published in the recent years. The third section described the methodological framework and the assumptions for the stress test parameters of the insurance scenarios. The fourth section showed the results of the stress testing. The main conclusions of the research are outlined in the fifth section, followed by the bibliography summarised in the sixth section.

\section{Literature review}

In the academic literature, the subject of the corporate governance and risk management in the insurance industry has been analyzed by many researchers. Bansal et al. (2014) provided a qualitative assessments of corporate governance and risk management strategies for different insurance industries around the world. Siri (2017) showed the regulatory trends in corporate governance of insurance companies from the emerging countries. Eling et al. (2009) evaluated the minimum capital requirements for an investment strategy of non-life insurance company based on various risk measures. Eckert et al. (2017) analyzed for a non- 
life insurance company the optimal risk- and value-based management decisions related to an investment strategy by maximizing shareholder applying preference functions.

Another strand of the literature presents the approaches for scenario design. For instance, Nagpal (2017) proposed a personalized approach to designing stress scenarios for a portfolio based on historical data for periods with the most stressful market changes with adverse impact for that portfolio. The designing stress scenarios approach showed the changes that had the greatest negative impact on portfolio performance due to possible market changes in the risk factors and asset classes. The approach can be personalized by including any specific market conditions such as increasing the interest, unemployment rate or other plausible market changes. Glasserman et al. (2015) to evaluate the financial risk, focusing on reverse stress tests developed a method to select and analyze stress scenario based on a nonparametric empirical likelihood estimator of the conditional mean of the market factors that underlie large losses. Breuer et al. (2009) suggested a measure of plausibility useful in the context of stress test for banking sector, tested for a portfolio of adjustable-rate loans national and foreign currency that is not prone to the dimensional dependence of maximum loss, in which only some risk factors are stressed.

Stress testing is often used by regulators to quantify the potential impact of hypothetical adverse scenarios under a specific market. For example, European Insurance and Occupational Pensions Authority (EIOPA) launched four stress test exercises (in the years 2011, 2014, 2016 and 2018) to assess the vulnerability of the European insurance sector. In the recent years, motivated by the implementation of the Solvency II framework regulatory, many articles relating to the stress tests in the insurance industry have been published in the financial literature around the world. For instance, Borel-Mathurin et al. (2017) studied the implications of the tail quantile and loss absorbing capacities reestimation on post-stress solvency coverage ratios. They proposed a stylized model of the solvency capital requirement re-evaluating after the occurrence of large events and a set of policy recommendations for insurance supervisors.

In 2015, Romanian Financial Supervision Authority (ASF) in cooperation with EIOPA carried out a balance sheet review and a test stress exercise with reference date 30th of June 2014, to assess the vulnerabilities on the Romanian insurance sector before the introduction of Solvency II regime under different insurance stress scenarios (five singlefactor scenarios) and market stress scenarios (simultaneous six shocks), based on the adjusted Solvency II Balance Sheets input data from the balance sheet review exercise. The results of the stress testing demonstrated the vulnerability of the Romanian insurance sector (the participating insurers did not have sufficient capital), the insurance stress scenario having the most significant impact.

\section{Methodology}

The basis of the scenario testing was a non-life insurer that operating on the Romanian insurance market. The stress-scenarios were carried out based on the fictitious Solvency II Balance Sheets input data of the undertaking at the reference date 31th of December 2017. The input data for the stylized insurance portfolio was build based on the annual reports of the five representative large Romanian non -life insurance companies at the reference date 31th of December 2017 available on their websites. At the end of 2017 year, the top five 
insurers accounting for $70,03 \%$ of the non-life Romanian insurance industry, therefore the input data for the built insurance portfolio is representative for the Romanian insurance market. To validate the accuracy of the data used, the results of the research have been compared with the results of a test stress exercise performed by ASF in 2015 year for each of the top five insurers and the conclusions are similar. The information with respect to the Romanian non-life insurance market was obtained from the industry reports provided by ASF and EIOPA.

\section{Methodological framework}

The stress scenarios were performed according to the Standard Formula based on Solvency II regime approach proposed by EIOPA. In conformity with the Solvency II framework, the capital requirements are known as Solvency Capital Requirement (SCR) and Minimum Capital Requirement (MCR) and the equity capital is known as own founds.

\section{Solvency capital requirement (SCR)}

The Solvency II Standard Formula applied a modular structure to calculate the SCR. The overall risk exposure of the insurer is split up into risk modules, subrisks and subsubrisks. For each risk/subrisk module is calculated the capital requirements. Afterwards, these capital requirements, by using a correlation matrices, are aggregated into an overall solvency capital requirement. Figure 1 presented an overview of the Solvency II Standard Formula structure.

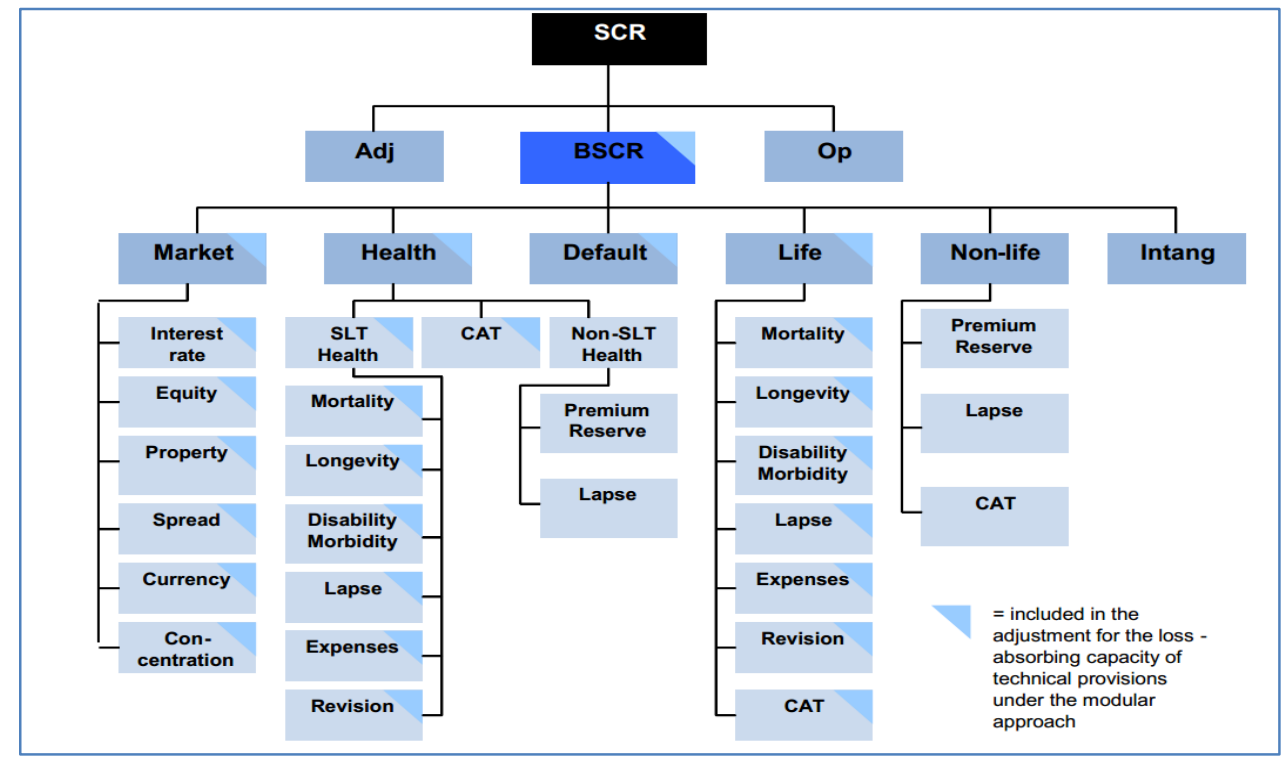

Figure 1. Solvency II Standard Formula Structure

Source: European Insurance and Occupational Pensions Authority, 2014, p.6 formula:

The Basic Solvency Capital Requirement (BSCR) is calculated based on the following

$$
B S C R=\sqrt{\operatorname{Corr}_{\text {Basic }(i, j)} \cdot S C R_{i} \cdot S C R_{j}}
$$


where:

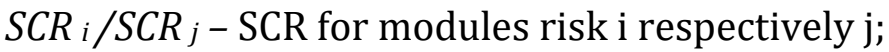

$\operatorname{Corr}_{\text {Basic }(\mathrm{i}, \mathrm{j})}$ - correlation factor provided by EIOPA;

In the calculation, $\mathrm{i}$ and $\mathrm{j}$ are replaced by: non-life underwriting, life underwriting, health, market and counterparty default risk modules.

SCR for non-life underwriting risk is calculated applying the following formula:

PICBE | 153

$$
S C R_{N L}=\sqrt{\operatorname{Corr}_{N L(i, j)} \cdot S C R_{i} \cdot S C R_{j}}
$$

Where:

$S C R_{i} / S C R_{j}$ - SCR for submodules risk i respectively j;

$\operatorname{CorrNL}_{(i, j)}$ - correlation factor provided by EIOPA;

In the calculation, $\mathrm{i}$ and $\mathrm{j}$ are replaced by: premium and reserve, lapse and catastrophe submodules risk.

The scenario testing of the article is focused only on the non-life underwriting risk module (premium and reserve and catastrophe risk submodules). The lapse risk has not been taken into account in the research due to that usually in non-life insurance the lapse risk has an immaterial impact in the SCR for Non-Life underwriting risk, the premium and reserve and catastrophe submodules have generally a prominent weight on SCR calculation.

SCR for non-life premium and reserve risk is defined by the following formula:

where:

$$
S C R_{N L \text { Prem Res }}=3 \cdot \sigma_{N L \text { Prem Res }} \cdot V_{N L \text { Prem Res }}
$$

$\sigma_{\mathrm{NL}}$ Prem Res - standard deviation for premium and reserve;

$V_{\mathrm{NL} \text { Prem Res }}$ - volume measure for premium and reserve;

The SCR for non-life catastrophe risk is defined by the following formula:

$$
S C R_{N L C A T}=\sqrt{\left(S C R_{\text {NatCat }}+S C R_{\text {Nproperty }}\right)^{2}+S C R_{\text {mmCat }}{ }^{2}+S C R_{\text {OtherCat }}{ }^{2}}
$$

Where:

SCR NatCat / SCR NpProperty / SCRmmCAT / SCRotherCAt - SCR for sub-sub risk modules: natural catastrophe, non-proportional property reinsurance, man-made respectively other non-life.

\section{Minimum Capital Requirement (MCR)}

The MCR represents the minimum level below which the financial resources of an insurance company should not fall. The MCR is calculated independently of the SCR using a linear formula based on the factors (which varies by lines of business) applied to the volume of the best estimate of technical provisions and written premiums. The MCR has a floor, equivalent to $25 \%$ of the SCR, and a cap, equivalent to $45 \%$ of the SCR. Also, there is an absolute floor of 3.7 million EUR.

\section{Own funds}

Under the Solvency II regime the equity capital is equivalent to the excess of assets over liabilities is known as available own funds. The proportion of the available own funds which are able to cover the SCR and MCR are designated as eligible own funds. The ratios of eligible own funds to cover the SCR and MCR are known as SCR ratio, respectively MCR ratio. According to Solvency II framework the SCR ratio and MCR ratio should be at least $100 \%$. 
The own founds available are classifed into so-called tiers according to their quality: Tier 1 highest quality class are available at all times and without restriction to cover the SCR / MCR and Tier 2 and Tier 3 that are capped to different limits. The eligible own funds to meet SCR can by maxim 50\% Tier 2 and Tier 3 and in addition maxim 15\% Tier 3. The eligible own funds to meet MCR can be maxim 20\% Tier 2 and Tier 3 is not creditable.

PICBE | 154

\section{Insurance scenario assumptions}

Natural catastrophe scenario assumptions

Methodological framework for the natural catastrophe stress scenario consists in two distinct scenarios: earthquake and flood, which were carried out separately and on an aggregate basis. The shock parameters of the natural catastrophe stress scenarios correspond to three stress factors that have been applied distinct and combined (as a set of risk tests):

1. $+15 \%$ applied on the provided gross probable maximum loss (PML) corresponding by an increase with $15 \%$ of a severity of PML compared to 1-in-200 event calculated according to Standard Formula approach;

2. $+5 \%$ applied on the gross best estimate claim provisions for natural catastrophe reserving risk;

3. Reinsurer's incapacity to pay (reinsurer's insolvency).

Business scenario assumptions

This scenario was performed based on the following shock stress test parameters:

1. $+3 \%$ claims provisions due to the impact of inflation;

2. $+10 \%$ gross earned premium only for motor third party liability (MTPL) portfolio due to the legislative changes;

3. $+15 \%$ claims provisions only for MTPL portfolio due to the growing frequency and severity of the losses induced by the increased exposure as a result of the lower premiums;

4. $-10 \%$ applied on the ceded best estimate technical provisions;

The scenarios analysis process has included the following stages: pre stress overview of the insurer solvency position (risk profile, own funds, SCR and MCR) and the post-stress scenarios impact on the company solvency position (the movements on own founds, SCR and MCR ratios under each insurance scenarios).

\section{Results and discussions}

\section{Pre Stress Situation}

With regard to the business activity, the company analyzed is engaged only in non- life insurance risks and operates exclusively on the Romanian insurance market. At the end of 2017, the main lines of business underwriting in the insurer's portfolio are motor and fire, accounting for $97 \%$ of the total business, with a significant exposure on the MTPL line of business $(73 \%$ of the gross written premiums). As a consequence, this high concentration was the main risk factor for the non-life underwriting risk module of solvency capital requirements. The risk profile that is heavily weighted to motor insurance risks and more specifically motor third party liability is not expected to change significantly over the near term whereas Romanian insurance market is dominated by motor insurance business. 
The total net SCR of the insurer amounts to 45 million EUR. The main components of the SCR are non-life underwriting risk ( $67 \%$ of the total BSCR), followed by the market risk ( $23 \%$ of the total BSCR) and counterparty default risk (10\% of the total BSCR). The significant exposure of the Non-Life underwriting risk module was expected taking into account the dominance of the MTPL portfolio in the insurance company portfolio. An overview of the SCR by risk component is set out below:

PICBE $\mid 155$

Table 1: SCR insurance company by risk components

\begin{tabular}{|l|c|}
\hline Solvency Capital Requirement by risk component & EUR thousand \\
\hline Market risk & 11.232 \\
\hline Counterparty default risk & 4.624 \\
\hline Non-life underwriting risk & 32.109 \\
\hline Diversification & 8.808 \\
\hline BSCR & 39.157 \\
\hline Operational risk & 5.768 \\
\hline SCR & 44.925 \\
\hline
\end{tabular}

The solvency capital requirement is heavily weighted to the non-life underwriting risk. Premium and reserve risk represents $87 \%$ from total non-life underwriting risk, due to the high level of premium and reserve risk is the structure of the company's portfolio with a significant exposure to the motor insurance segment (especially MTPL). The MTPL insurance policies recorded a negative dynamics at the level of gross written premiums in the last year due to the decrease of the average premium, in the context of legislative changes.

Through the insurance contracts underwritten, the company is exposed also to the risks of natural catastrophes and man-made. Considering that the business underwriting by the insurer is located in Romania, the company is exposed on two natural catastrophe risks, earthquakes and floods. By far the biggest risk of the gross SCR for the natural catastrophe events is represented by earthquake, the gross SCR from flood perils is less high. These risks are mitigated by an adequate / prudently reinsurance programs and the net SCR generated by earthquake and floods events is considerably lower. SCR for non-life underwriting risk by risk components is shown in the flowing table:

Table 2: Non-life underwriting risk SCR components
\begin{tabular}{|l|c|}
\hline Non-life underwriting risk & EUR thousand \\
\hline Premium and reserve risk & 30.903 \\
\hline Catastrophe risk & 3.920 \\
\hline Diversification & - \\
\hline Total non-life underwriting risk SCR & 32.109 \\
\hline
\end{tabular}

Source: Authors' own research

The excess of assets over liabilities of the insurer amounts to 64.5 million EUR. Tier 1 own funds accounting for $93 \%$ of overall own-funds, indicating the high quality of the insurance company own funds. The SCR ratio is $144 \%$, representing an excess of 19.6 million EUR of own funds held over the SCR and MCR ratio is $372 \%$, representing an excess of 45.9 million EUR of own funds held over the MCR. In the following table it is presented the structure of 
own funds held by the company, the eligible own funds to meet SCR/MCR taking into account the restrictions of the tiers and the ratio of eligible own funds over the MCR and SCR.

Table 3: Own funds structure

\begin{tabular}{|c|c|c|c|c|c|}
\hline $\begin{array}{l}\text { Own funds structure (EUR } \\
\text { thousand) }\end{array}$ & Total & $\begin{array}{l}\text { Tier } 1 \\
\text { unrestricte } \\
\text { d }\end{array}$ & $\begin{array}{l}\text { Tier } 1 \\
\text { restricted }\end{array}$ & Tier 2 & Tier 3 \\
\hline Available own funds & 64.505 & 60.020 & 0 & 4.485 & 0 \\
\hline Eligible own funds to meet SCR & \multicolumn{5}{|c|}{64.505} \\
\hline Eligible own funds to meet MCR & \multicolumn{5}{|c|}{62.937} \\
\hline SCR & \multicolumn{5}{|c|}{44.925} \\
\hline MCR & \multicolumn{5}{|c|}{17.033} \\
\hline SCR Ratio & \multicolumn{5}{|c|}{$144 \%$} \\
\hline MCR Ratio & \multicolumn{5}{|c|}{$372 \%$} \\
\hline
\end{tabular}

Source: Authors' own research

\section{Post Stress Results}

This section presented the results of each insurance stress scenarios separately and aggregated. The objective of the testing is the post-stress scenarios impact on own funds and solvency ratios.

\section{Natural Catastrophe Stress Scenario}

In the table below are summarized the results of the natural catastrophe stress scenario that have been performed independently to the business stress scenario. The results are presented both separately and aggregated earthquake and flood scenario.

Table 4: Natural Catastrophe Stress Scenario results

\begin{tabular}{|c|c|c|c|c|c|c|}
\hline \multicolumn{2}{|c|}{ Scenario (EUR thousand) } & $\begin{array}{l}\text { Pre- } \\
\text { stress }\end{array}$ & $\begin{array}{l}\text { Impact } \\
+15 \% \\
\text { PML }\end{array}$ & $\begin{array}{l}\text { Impact } \\
+5 \% \mathrm{BE}\end{array}$ & $\begin{array}{l}\text { Impact } \\
\text { reinsurer' } \\
\text { s } \\
\text { insolvency }\end{array}$ & $\begin{array}{l}\text { Aggregate } \\
\text { d impact }\end{array}$ \\
\hline \multirow{3}{*}{$\begin{array}{l}\text { Earthquak } \\
\mathrm{e}\end{array}$} & SCR & 44.925 & 45.091 & 44.944 & 62.182 & 66.057 \\
\hline & Excess of own funds over SCR & 19.580 & 19.414 & 19.161 & 2.323 & -1.952 \\
\hline & SCR Ratio Earthquake & $\begin{array}{r}143,58 \\
\%\end{array}$ & $\begin{array}{r}143,05 \\
\% \\
\end{array}$ & $\begin{array}{r}142,63 \\
\% \\
\end{array}$ & $103,74 \%$ & $97,04 \%$ \\
\hline \multirow{3}{*}{ Flood } & SCR & 44.925 & 44.957 & 44.944 & 46.954 & 47.510 \\
\hline & Excess of own funds over SCR & 19.580 & 19.549 & 19.161 & 17.551 & 16.595 \\
\hline & SCR Ratio Flood & $\begin{array}{r}143,58 \\
\%\end{array}$ & $\begin{array}{r}143,48 \\
\%\end{array}$ & $\begin{array}{r}142,63 \\
\%\end{array}$ & $137,38 \%$ & $134,93 \%$ \\
\hline \multirow{3}{*}{$\begin{array}{l}\text { Earthquak } \\
\text { e \& Flood }\end{array}$} & SCR & 44.925 & 45.121 & 44.944 & 62.950 & 66.984 \\
\hline & Excess of own funds over SCR & 19.580 & 19.385 & 19.161 & 1.556 & -2.879 \\
\hline & $\begin{array}{l}\text { SCR Ratio Earthquake \& } \\
\text { Flood }\end{array}$ & $\begin{array}{r}143,58 \\
\%\end{array}$ & $\begin{array}{r}142,96 \\
\% \\
\end{array}$ & $\begin{array}{r}142,63 \\
\% \\
\end{array}$ & $102,47 \%$ & $95,70 \%$ \\
\hline
\end{tabular}

\section{Earthquake Stress Scenario}

Source: Authors' own research

The severity of the net impact of the earthquake stress scenario is determined by the characteristics of each parameter applied. The parameters: increasing by $15 \%$ of the gross PML and increasing by $5 \%$ of the gross best estimate claim provisions for natural catastrophe reserving risk did not have a materially impact on the company's solvency position. Growing of SCR as a result of applying these shock factors is insignificant: 0, 17 million EUR for 15\% 
gross PML increasing and 0,019 million EUR for 5\% gross best estimate claim provisions increasing. This is due to the small exposure of the insurance company on this line of business. About $8,6 \%$ of the total gross written premiums and $5 \%$ of the total gross best estimate claim provisions correspond to "fire and other property damage" line of business and hence the impact is immaterial.

The effect on the scenario in which it is applied the factor "reinsurer's incapacity to

PICBE $\mid 157$ pay" is severe. This scenario has led to an increase in SCR by 38\% up to 62,2 million EUR but the insurer is still solvable, SCR ratio exceeding the threshold of $100 \%(103,74 \%)$.

The earthquake stress scenario in which have been applied all three parameters as a set of stress factors: increasing by $15 \%$ of PML, increasing by $5 \%$ of the gross best estimate claim provisions and reinsurer's incapacity to pay, is severe for the insurance company, resulting in an increase in SCR by $47 \%$ up to 66, 06 million EUR and non-compliance of the solvency capital requirements (SCR ratio is $97 \%$ ).

\section{Flood Stress Scenario}

The flood stress scenario is less severe than the earthquake scenario. After the application of the all three stress factors: increasing by $15 \%$ of PML, increasing by $5 \%$ of the gross best estimate claim provisions and reinsurer's incapacity to pay, the results of the testing shown a moderate impact on the insurer solvency capital requirements: SCR have increased only by $6 \%$ up to 47, 5 million EUR and the company has met the solvency capital requirements. As in earthquake scenario, impact of increasing by $15 \%$ of PML and $5 \%$ of the gross best estimate claim provisions was limited, the biggest impact factor remaining reinsurer's incapacity to pay.

\section{Earthquake \& Flood Scenario}

The aggregated earthquake and flood scenario is the most severe natural catastrophe scenario for the insurance company. After the application of the three stress factors, the results of the testing shown an increase in SCR by $49 \%$ up to 67 million EUR and noncompliance of the solvency capital requirements (SCR ratio is 95,7\%). Similar conclusions as in the separately earthquake and flood scenarios can be derived for the aggregated scenario: the impact of increasing by $15 \%$ of PML and $5 \%$ of the gross best estimate claim provisions was limited, the biggest impact factor remaining reinsurer's incapacity to pay, which underline the importance of a reinsurance quality for insurance companies.

The figure below shown the impact of the natural catastrophe stress scenario on the SCR ratio 


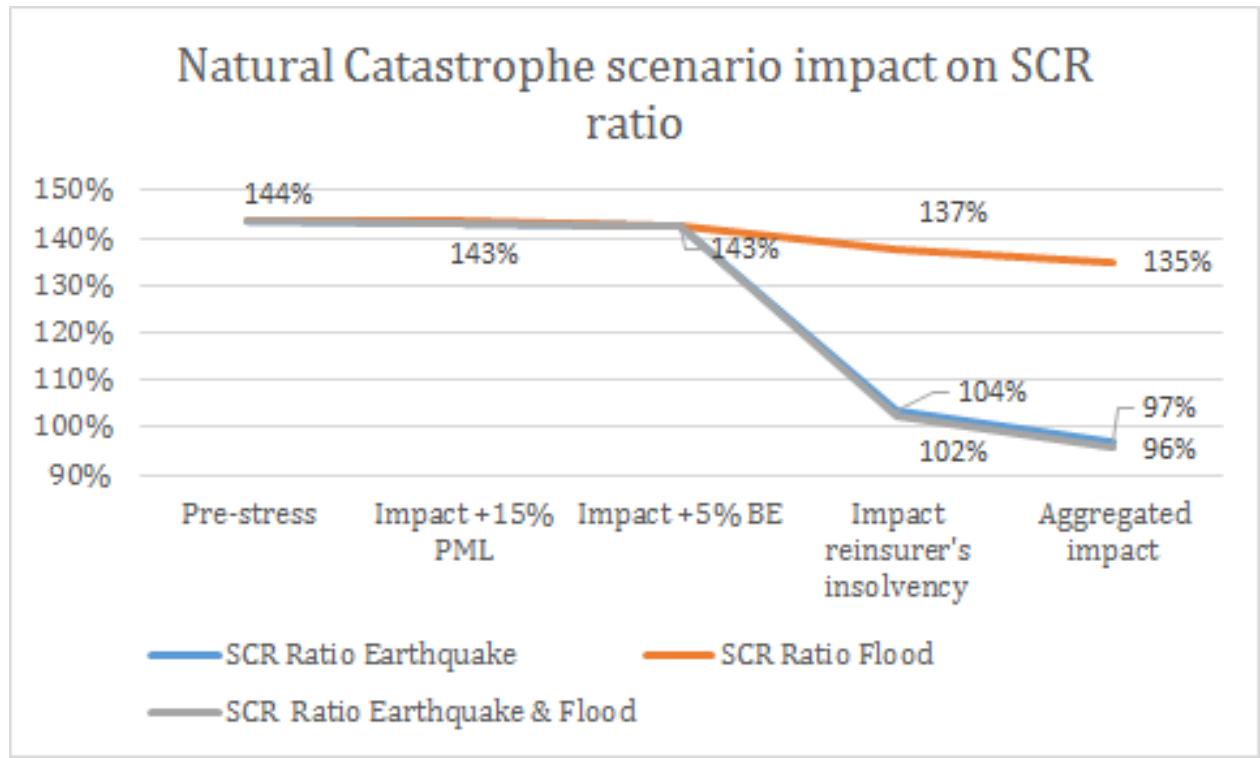

PICBE | 158

Figure 2. Natural Catastrophe scenario impact on SCR ratio

\section{Business scenario}

Source: Authors' own research

The insurance company is more sensitive to business stress scenario, compared to natural catastrophe stress scenarios due to the heavily weighted of premium and reserve risk submodule and the significant exposure on the MTPL line of business. In the table below are presented the results of the business stress scenario.

\begin{tabular}{|c|c|c|c|c|c|c|}
\hline $\begin{array}{l}\text { Business scenario (EUR } \\
\text { thousand) }\end{array}$ & $\begin{array}{l}\text { Pre- } \\
\text { stress }\end{array}$ & $\begin{array}{l}\text { Impact } \\
+3 \% \\
\text { inflatio } \\
\text { n }\end{array}$ & $\begin{array}{l}\text { Impac } \\
\mathrm{t} \\
+10 \% \\
\text { EP } \\
\text { MTPL } \\
\end{array}$ & $\begin{array}{l}\text { Impact } \\
+\mathbf{1 5 \%} \\
\text { BE } \\
\text { claims } \\
\text { MTPL } \\
\end{array}$ & $\begin{array}{l}\text { Impact - } \\
15 \% \text { BE } \\
\text { claims }\end{array}$ & $\begin{array}{l}\text { Aggregat } \\
\text { ed } \\
\text { impact }\end{array}$ \\
\hline Available own funds & 64.505 & 60.925 & 64.505 & 49.199 & 55.608 & 36.722 \\
\hline $\begin{array}{l}\text { Eligible own funds to meet } \\
\text { SCR }\end{array}$ & 64.505 & 60.925 & 64.505 & 49.199 & 55.608 & 36.722 \\
\hline $\begin{array}{l}\text { Eligible own funds to meet } \\
\text { MCR }\end{array}$ & 62.937 & 59.357 & 62.937 & 47.631 & 54.040 & 35.154 \\
\hline SCR & 44.925 & 45.599 & 48.521 & 48.136 & 46.073 & 53.568 \\
\hline MCR & 17.033 & 17.337 & 17.033 & 18.334 & 17.796 & 19.401 \\
\hline SCR Ratio & $144 \%$ & $134 \%$ & $133 \%$ & $102 \%$ & $121 \%$ & $69 \%$ \\
\hline MCR Ratio & $372 \%$ & $346 \%$ & $372 \%$ & $264 \%$ & $307 \%$ & $186 \%$ \\
\hline
\end{tabular}

The aggregate business stress scenario suggested a significant negative impact on the insurer balance sheet and the non-compliance of the solvency capital requirements. The 
results of the testing indicated a devaluation of own funds by $43 \%$ (27, 8 million EUR) and an increase of the SCR by $19 \%$ (8, 6 million EUR). The SCR ratio drops significant from 144\% to $69 \%$, whereas the MCR ratio drops from $372 \%$ to $186 \%$.

The impact of each shock stress factors is presented separately bellow:

1. "Increasing by $3 \%$ of the claims provisions due to the impact of inflation" affects the overall portfolio of the company. The effect of this scenario is moderate, resulting in a devaluation of own funds by 3, 6 million EUR, an increase of SCR by 0, 6 million EUR and a drop in SCR ratio by $10 \%$.

2. "Increasing by $10 \%$ of the gross earned premium due to the legislative changes" affects only the MTPL portfolio. Similar as in the scenario above, the impact of this scenario is moderate, resulting in an increase of SCR by 3, 6 million EUR, own funds were not affected and a drop in SCR ratio by $11 \%$.

3. "Increasing by $15 \%$ of the claims provisions due to the increase of frequency and severity of the losses induced by the exposure increase as a result of the lower premiums" affects only the MTPL portfolio. The impact of this scenario is high, resulting in a devaluation of own funds by $24 \%$ (15, 3 million EUR), an increase of SCR by 3, 2 million EUR and a drop in SCR ratio by $41 \%$.

4. "Decreasing by $10 \%$ of the ceded best estimate" affects the overall portfolio of the company. This scenario presents more significant impact compared to the first two scenarios above, resulted in a devaluation of own funds by $14 \%$ (8,9 million EUR), an increase of SCR by 1,1 million EUR and a drop in SCR ratio by $23 \%$.

The figure below presented the impact of the business stress scenario on the SCR ratio and MCR ratio.

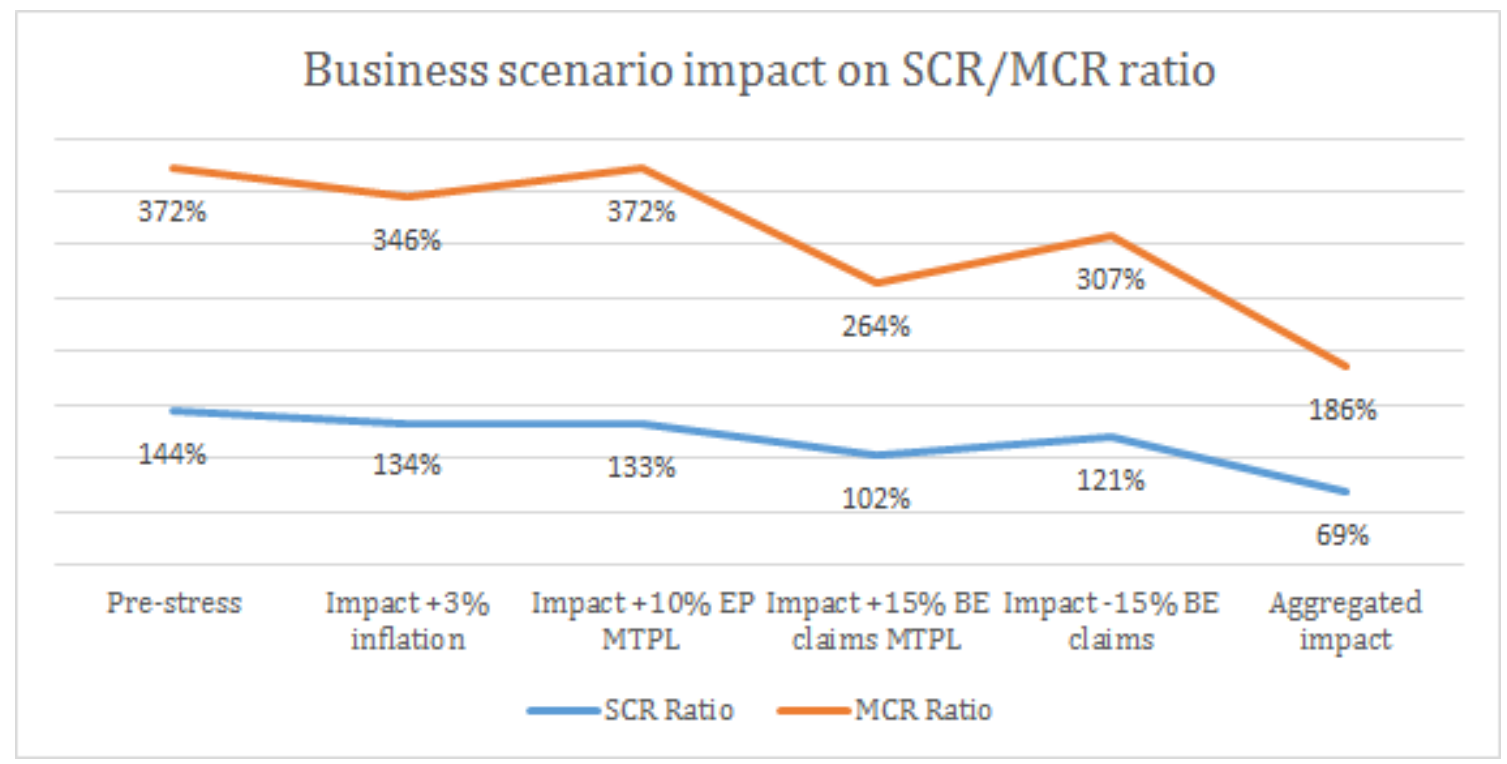

Figure 3. Business scenario impact on SCR ratio and MCR ratio

Source: Authors' own research 


\section{Conclusion}

Stress test scenarios represent a powerful management tool to evaluate the potential risks to which the business of an insurance company can be exposed in realistic and adverse future situations, that help the insurer to focus on the question as "How should manage the risks in the occurrence of event X?"

Due to geographical conditions, high exposure to earthquake risk is a characteristic for Romania and it was expected that stress test results to confirm this. Conclusions on the vulnerability of the insurance company with respect to the natural catastrophe stress scenario results indicated that the entity did not meet the solvency capital requirements under the assumption of earthquake and aggregated earthquake and flood scenarios due to the biggest impact factor has reinsurer's incapacity to pay. Therefore, the quality of reinsurance is very important for Romanian insurance companies to be able to manage the risks arising from the seismic events and to be fully compliant the regulatory solvency capital requirements in these situations. The results of the flood stress scenario testing showed a moderate impact on the insurer solvency position and the compliance of the solvency capital requirements.

The insurance company is more sensitive to business stress scenario, compared to natural catastrophe stress scenarios due to the heavily weighted of premium and reserve risk submodule and the significant exposure on the MTPL line of business.

\section{References}

Bansal, B., Bansal, A. (2014). Corporate Governance and Risk Management in Insurance Sector: A review of literature. International Journal of Scientific and Research Publications, 4 (10), 1-3

Borel-Mathurin, F., Loisel, S., Segers, J. (2017). Re-evaluation of the capital charge in insurance after a large shock: empirical and theoretical views. Université catholique de Louvain, ISBA, Discussion paper 2017/06

Breuer, T., Jandacka, M., Rheinberger, K., Summer, M. (2009). How to Find Plausible, Severe, and Useful Stress Scenarios. International Journal of Central Banking 5 (3) 205-224

Eckert, J., Gatzert N. (2018). Risk- and value-based management for non-life insurers under solvency constraints. Risk Management 19 (2017) 323-349, European Journal of Operational Research 266 (2018) 761-774

Eling, M., Gatzert, N., Schmeiser, H. (2009). Minimum standards for investment performance: A new perspective on non-life insurer solvency. Insurance: Mathematics and Economics, 45(1), 113-122.

Fröhlich, A., Weng, A. (2017). Parameter uncertainty for risk capital calculations for aggregated insurance portfolios. Available under http://versicherung-m mathematik.de/wp-content/uploads/2017/03/Article_Multinormal_preprint.pdf

Nagpal, K.M. (2017). Designing stress scenarios for portfolios. Risk Management 19 (2017) 323-349, published online https://doi.org/10.1057/s41283-017-0024-x

Siri, Michele (2017) : Corporate governance of insurance firms after Solvency II, ICIR Working Paper Series, No. 27/17

European Insurance and Occupational Pensions Authority (2014). The underlying assumptions in the standard formula for the Solvency Capital Requirement 
calculation, available at: https://eiopa.europa.eu/Publications/Standards/EIOPA14-322_Underlying_Assumptions.pdf

Financial Supervision Authority (2015).Balance Sheet Review and Stress Tests of the Romanian insurance market, available at: www.asf.ro

Financial Supervision Authority (2018). The evolution of the Romanian insurance market in 2017, available at: www.asf.ro

PICBE | 161

Official Journal of the European Union (2009). Directive 2009/138/EC of the European Parliament and of the Council of 25 November 2009 on the taking-up and pursuit of the business of Insurance and Reinsurance (Solvency II), available at: http://eurlex.europa.eu/legal-content/EN/TXT/PDF/?uri=CELEX:32009L0138\&from=EN

Official Journal of the European Union (2015). COMMISSION DELEGATED REGULATION (EU) 2015/35 of 10 October 2014 supplementing Directive 2009/138/EC of the European Parliament and of the Council on the taking-up and pursuit of the business of Insurance and Reinsurance (Solvency II), available at: https://eurlex.europa.eu/legal- content/EN/TXT/PDF/?uri=0J:L:2015:012:FULL\&from=EN 